\title{
Environmental Evaluation of Coal Mines Based on Generalized Linear Model and Nonlinear Fuzzy Analytic Hierarchy
}

\author{
Xueming Du $\mathbb{D}^{1,2,3}$ Hongyuan Fang $\mathbb{D}^{1,3}$ Kang Liu, ${ }^{1,3}$ Binghan Xue $\mathbb{D}^{1,3}$ and Xin Cai $\mathbb{D}^{2}$ \\ ${ }^{1}$ College of Water Conservancy Engineering, Zhengzhou University, Zhengzhou 450001, China \\ ${ }^{2}$ School of Resources and Safety Engineering, Central South University, Changsha, Hunan 410083, China \\ ${ }^{3}$ National Local Joint Engineering Laboratory of Major Infrastructure Testing and Rehabilitation Technology, \\ Zhengzhou 450001, China
}

Correspondence should be addressed to Hongyuan Fang; 18337192244@163.com and Binghan Xue; zzuhan@163.com

Received 24 March 2020; Revised 5 August 2020; Accepted 26 August 2020; Published 23 September 2020

Academic Editor: Ilaria Fuoco

Copyright (c) 2020 Xueming Du et al. This is an open access article distributed under the Creative Commons Attribution License, which permits unrestricted use, distribution, and reproduction in any medium, provided the original work is properly cited.

To create a good working environment for workers in coal mines and ensure that they can work safely and comfortably, environmental assessments of coal mines represent an important method used to achieve this goal. In this paper, a comprehensive environmental evaluation model of coal mines was established based on generalized linear theory and fuzzy analytic hierarchy processes. First, the importance degree of each index factor was obtained by analyzing the statistical source data of air, water, soil, ecological compensation, and other indexes that affect the ecological environmental safety of coal mines using generalized linear theory. Based on the importance degree of each index factor, a pairwise comparison matrix was constructed by the logarithmic fuzzy preference programming method, and the influence weight value of each index factor was accurately obtained through MATLAB software. The results indicated that the model can effectively reduce the impact of expert subjectivity on the evaluation results, which is consistent with the reality of coal mines. In addition, in the process of environmental assessment of coal mines, the model is proven to be convenient, precise, and easy to operate.

\section{Introduction}

Resource safety is an important part of national strategic safety, and the development of mineral resources is always an important mission [1-3]. In particular, in the past 30-40 years, the development of mineral resources has provided strong support and protection for the rapid development of the economy and society. Due to technological reasons and the pursuit of high profits, the strength of mine ecological protection and restoration management has not been as strong as people would prefer, leading to the intensification of the contradiction between the coal mine development and ecological safety, e.g., the high production rate of three wastes of coal mines, the long potential harm of radiation, and the serious pollution to the air, water and soil [2]. In particular, the disordered development in some areas has led to geological disasters, such as surface collapse and debris flow, which have intensified land desertification and led to the degradation of ecological environmental quality [3]. Therefore, it is urgent to explore a new technology of mine geological environmental governance and ecological restoration to prevent the further degradation of ecological health. The current ecological environmental safety assessment of coal mines can not only measure the overall status of the ecological quality of coal mines but also reflect the governance of the ecological environmental pollution. Additionally, it can quickly identify the important factors that cause the deterioration of the mine environment, allowing for the quick adoption of the most effective measures to control the "culprits" that make the mine environment worse.

Currently, many scholars have constructed a series of safety evaluation models, e.g., analytic hierarchy process, fuzzy comprehensive evaluation, grey theory, and neural network method, and applied them to mine ecological environmental safety evaluations. For instance, Zhao et al. [4] established an evaluation index system of the mine geological environment using the analytic hierarchy process (AHP) and applied this method to the mining field of Hainan Island; the 
TABLE 1: Scale of triangular numbers with different importance.

\begin{tabular}{lcc}
\hline Logical variable & Scale of TFN & Reciprocal scale of TFN \\
\hline Equally important & $(1,1,1)$ & $(1,1,1)$ \\
Weakly important & $(1 / 2,1,3 / 2)$ & $(2 / 3,1,2)$ \\
Fairly important & $(1,3 / 2,2)$ & $(1 / 2,2 / 3,1)$ \\
Strongly important & $(3 / 2,2,5 / 2)$ & $(2 / 5,1 / 2,2 / 3)$ \\
Very strongly important & $(2,5 / 2,3)$ & $(1 / 3,2 / 5,1 / 2)$ \\
Extremely important & $(5 / 2,3,7 / 2)$ & $(7 / 2,1 / 3,2 / 5)$ \\
\hline
\end{tabular}

authors found that the evaluation value basically conformed to the situation of the mine site. Bascetin et al. [5] constructed a decision support system based on an analytical hierarchy process to evaluate the production of coal mines in Turkey. Samantra et al. [6] created an improved decision method based on fuzzy set theory and distinguished the ranges of evaluated risk ratings, ultimately suggesting an action requirement plan to guide the management of the mine environment. Yang et al. [7] selected four factors that affect the mine environment, including the water environment, atmospheric environment, geological disaster, and ecological environmental characteristics, as the evaluation factors to build a fuzzy comprehensive evaluation model of the mine environment for the quantitative study of the mine environment. Su et al. [8] established an engineering geological evaluation model based on grey mathematics theory and evaluated the engineering geological situation of typical mines by determining the evaluation weight index. Zhao et al. [9] used the principle of BP neural networks and the random interpolation method to build an evaluation model of the BP artificial neural network on mine ecological safety.

Each evaluation model has its own shortcomings. To fully consider the influence of all factors and present the comprehensive evaluation results scientifically and accurately, many scholars have combined various models to carry out comprehensive evaluations according to the characteristics of the different models, namely, the combined comprehensive evaluation model. For instance, based on fuzzy theory, Chen et al. [10] collected the key factors influencing the mine environment by remote sensing technology, determined the influence weight of the environmental evaluation factors by using AHP, and finally built the AHP-fuzzy mine environment evaluation model. Besides, Wei et al. [11] established the comprehensive evaluation of the underground heat source based on the AHP and fuzzy comprehensive evaluation (FCE) to construct the evaluation model, and some suggestions on thermal stress control are put forward. Based on the theories of uncertainty measurement evaluation (WME) and AHP, Dong et al. [12] established the comprehensive risk evaluation of underground goafs using multiple indexes. Dong et al. [13] also established and calibrate the comprehensive models using the random forest, support vector machine, Bayes' classifier, Fisher's classifier, logistic regression, and neural networks. Based on grey system theory, Wei et al. [14] used the analytic hierarchy process to determine the weight of each influencing factor and constructed a grey comprehensive evaluation model of the mine geological environment. To scientifically and accurately obtain the

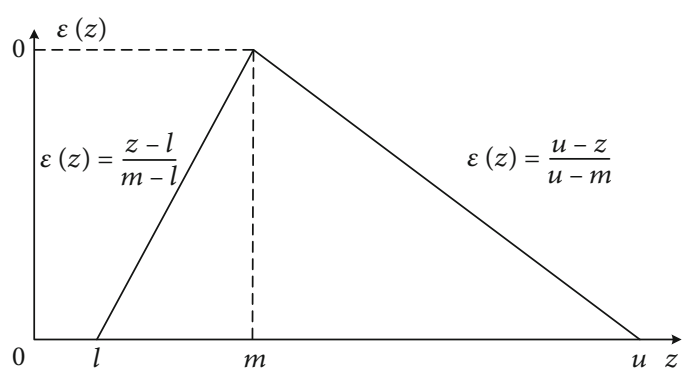

FIgURE 1: Triangular fuzzy number.

membership degree of each influencing factor, Liu et al. [15] built a fuzzy-grey combination evaluation model based on grey correlation analysis and fuzzy evaluation theory.

However, there are many factors that affect ecological environmental safety, and the relationship between the evaluation factors and the safety level is fuzzy, which makes the shortcomings of the current evaluation model more obvious. For instance, although the neural network model can overcome the subjectivity of expert experience and ensure a higher accuracy of evaluation results, it is easy to fall into the dilemma of a local minimum and slow convergence speed in the calculation process of weight, and this method cannot address the relationships between various index factors clearly. Although the AHP and grey theory evaluation methods can deal with the relationship of each index well, they rely on the experience of experts for evaluation when determining the weight of influencing factors; therefore, they cannot avoid subjectivity. The fuzzy analytic hierarchy process is the best method to address the fuzzy relationship of all factors; however, it also cannot avoid the evaluation of experts when building the comparison matrix.

To overcome the subjectivity of evaluation experts in the evaluation of the influence degree of each index factor and to further improve the uncertainty of data processing, in this paper, a comprehensive evaluation model of the coal mine environment is established based on generalized linear theory and fuzzy level theory. First, the importance of each index in relation to the target index is obtained by the initial statistics of the source data of each lowest level index based on generalized linear theory. Then, according to the statistical value obtained by generalized linear theory, the pairwise comparison matrix is constructed by the logarithmic fuzzy preference programming method (LFPP). Finally, the influence weight value of each index factor is accurately obtained through MATLAB software. The model is applied to a coal mine for an environmental assessment.

\section{Methodology}

2.1. Triangular Fuzzy Number Theory. There are many kinds of distribution functions used to imitate probability theory, such as the normal distribution function, trapezoid distribution function, triangular fuzzy number, k-th parabola distribution, Cauchy distribution, and S-type distribution. The triangular fuzzy numbers (TFN) is widely adopted to express the decision perception of alternatives' performances with respect to each criterion [16]. In order to easy the judgment 


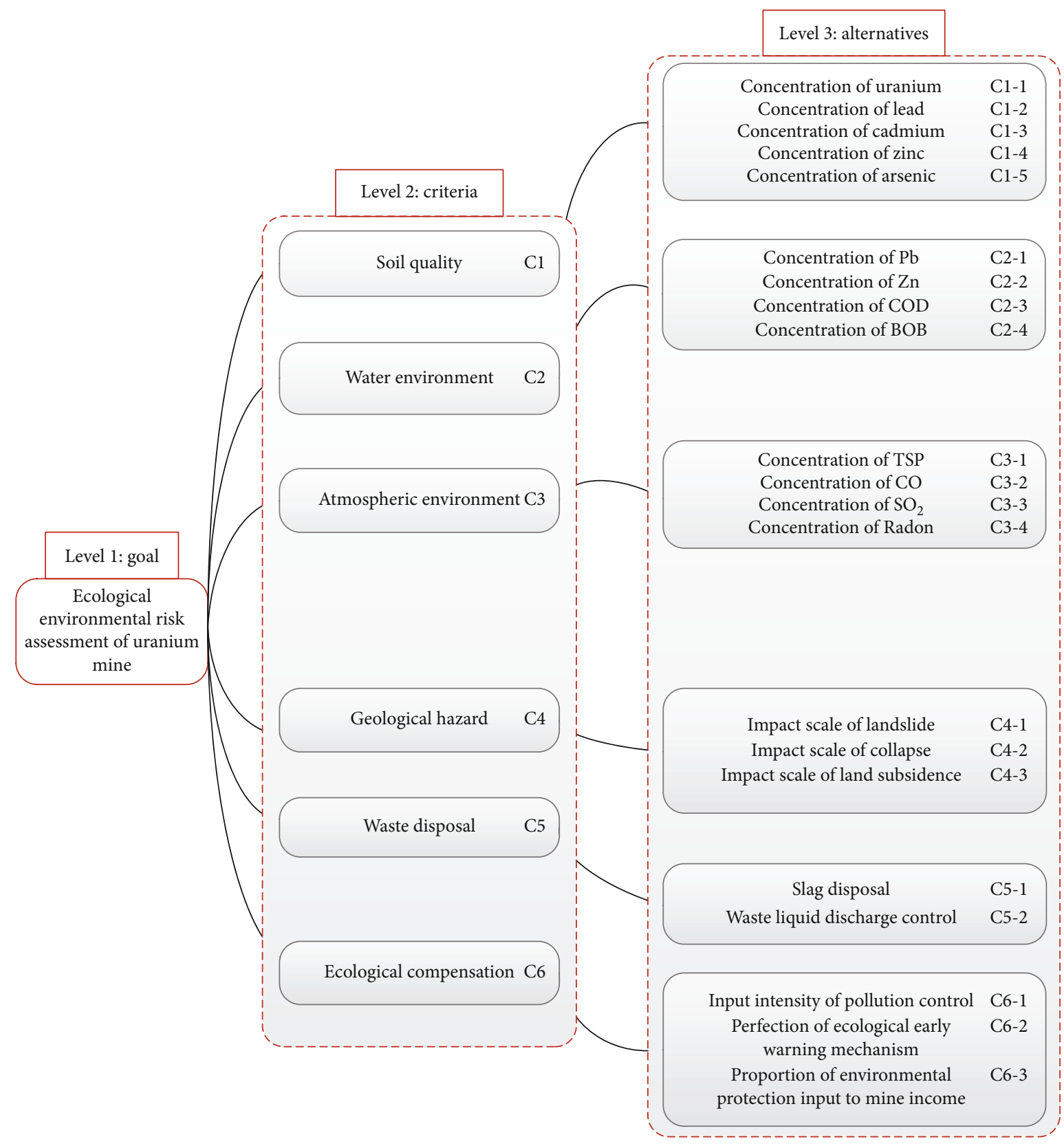

FIGURE 2: The diagram of environmental safety level analysis in coal mines.

TABLE 2: Statistical compensation indexes for mine ecological safety.

\begin{tabular}{ccccc}
\hline Year & $\begin{array}{c}\text { Input } \\
\text { intensity } \\
\text { of } \\
\text { pollution } \\
\text { control }\end{array}$ & $\begin{array}{c}\text { Improvement } \\
\text { of ecological } \\
\text { early warning } \\
\text { system }\end{array}$ & $\begin{array}{c}\text { Proportion of } \\
\text { environmental } \\
\text { protection } \\
\text { investment to } \\
\text { total income }\end{array}$ & $\begin{array}{c}\text { Synthetic } \\
\text { index of } \\
\text { compensation }\end{array}$ \\
\hline 2005 & 40.7 & 1.72 & 3.88 & 0.27 \\
2006 & 39.5 & 1.76 & 4.2 & 0.21 \\
2007 & 38.6 & 1.76 & 4.48 & 0.20 \\
2008 & 37.7 & 1.8 & 4.76 & 0.21 \\
2009 & 36.8 & 1.8 & 5.08 & 0.23 \\
\hline
\end{tabular}

process, linguistic variables are introduced (section 2.3), and it is a kind of variable whose values are not numbers but words and sentences [17]. Therefore, the triangular fuzzy theory is mainly used to build a model to evaluate the ecological environment of coal mines in this paper.

In a given region $Z$, for any $z \in Z$, the fuzzy set $A$ can be defined as

$$
A=\left\{\left(z, \varepsilon_{A}(z)\right) \mid z \in Z\right\}
$$

where $\varepsilon_{A}$ is the membership degree of $z$ to $A$ and $\varepsilon_{A}(x)$ $\in(0,1)$.

Let $l, m$, and $u$ be the minimum possible value, the intermediate value, and the maximum possible value of a certain 
TABLE 3: Statistics of influencing factors of atmosphere, soil, and water in coal mines.

\begin{tabular}{|c|c|c|c|c|c|c|c|c|c|c|c|c|c|c|c|}
\hline \multirow{2}{*}{ Point } & \multicolumn{4}{|c|}{ Atmosphere } & \multirow{2}{*}{$\begin{array}{l}\text { Synthetic index of } \\
\text { atmosphere }\end{array}$} & \multicolumn{5}{|c|}{ Soil } & \multicolumn{4}{|c|}{ Surface water } & \multirow{2}{*}{$\begin{array}{c}\text { Synthetic index of } \\
\text { water }\end{array}$} \\
\hline & TSP & $\mathrm{CO}$ & $\mathrm{SO}_{2}$ & $\mathrm{Rn}$ & & $\mathrm{Pb}$ & $\mathrm{Zn}$ & $\mathrm{Cd}$ & As & $\mathrm{U}$ & $\mathrm{Pb}^{2+}$ & $\mathrm{Zn}^{2+}$ & $\mathrm{COD}$ & $\mathrm{BOD}$ & \\
\hline 1 & 0.41 & 5.1 & 0.05 & 26.2 & 0.775 & 167.5 & 368 & 0.1 & 13.54 & 64.4 & 0.48 & 3.68 & 3.92 & 5.5 & 0.51 \\
\hline 2 & 0.23 & 3.12 & 0.09 & 34.4 & 0.625 & 234.9 & 888 & 0.3 & 10.96 & 62.9 & 0.66 & 5.32 & 14.3 & 12.7 & 0.45 \\
\hline 3 & 0.2 & 5.5 & 0.12 & 35 & 0.6 & 220 & 2339 & 0.6 & 9.63 & 56.8 & 0.57 & 4.43 & 15.6 & 17.1 & 0.26 \\
\hline 4 & 0.3 & 4.4 & 0.11 & 133 & 0.45 & 224.8 & 1521 & 0.7 & 14.47 & 54.7 & 0.60 & 4.31 & 22 & 16.8 & 0.2 \\
\hline 5 & 0.2 & 3.6 & 0.13 & 37.3 & 0.65 & 263.2 & 1267 & 0.4 & 12.1 & 60.3 & 0.52 & 5.07 & 24 & 19.1 & 0.2 \\
\hline 6 & 0.2 & 4.4 & 0.04 & 35.2 & 0.64 & 223.2 & 401.9 & 0.4 & 14.34 & 63.5 & 0.57 & 4.37 & 4.03 & 14.3 & 0.43 \\
\hline 7 & 0.15 & 3.2 & 0.13 & 38.1 & 0.51 & 244.8 & 986 & 0.3 & 12.76 & 61.7 & 0.56 & 5.22 & 14.3 & 10.7 & 0.49 \\
\hline 8 & 0.25 & 5.3 & 0.10 & 25.4 & 0.61 & 236.7 & 2021 & 0.8 & 14.63 & 53.9 & 0.61 & 3.83 & 16.7 & 19 & 0.27 \\
\hline 9 & 0.13 & 5.0 & 0.20 & 135 & 0.43 & 171.3 & 1320 & 0.7 & 12.87 & 56.3 & 0.47 & 4.03 & 23 & 21.1 & 0.21 \\
\hline 10 & 0.3 & 3.1 & 0.15 & 124 & 0.41 & 200.7 & 1268 & 0.5 & 12.1 & 62.3 & 0.58 & 5.11 & 21 & 20.2 & 0.2 \\
\hline
\end{tabular}

Synthetic index of soil.

TABLe 4: Importance of indicators at all levels to objectives.

\begin{tabular}{|c|c|c|c|c|}
\hline First level index & & Weight & Second level index & Weight \\
\hline \multirow{5}{*}{ Soil quality indicators } & \multirow{5}{*}{$\mathrm{C} 1$} & \multirow{5}{*}{0.393} & $\mathrm{~Pb} \mathrm{C1-1}$ & 0.319 \\
\hline & & & Zn C1-2 & 0.103 \\
\hline & & & $\mathrm{Cd} \mathrm{C1-3}$ & 0.117 \\
\hline & & & As $\mathrm{C} 1-4$ & 0.104 \\
\hline & & & $\mathrm{U}$ C1-5 & 0.357 \\
\hline \multirow{4}{*}{ Water environmental quality } & \multirow{4}{*}{$\mathrm{C} 2$} & \multirow{4}{*}{0.385} & $\mathrm{~Pb}^{2+} \mathrm{C} 2-1$ & 0.397 \\
\hline & & & $\mathrm{Zn}^{2+} \mathrm{C} 2-2$ & 0.183 \\
\hline & & & COD C2-3 & 0.207 \\
\hline & & & BOD C2-4 & 0.213 \\
\hline \multirow{4}{*}{ Atmospheric environmental } & \multirow{4}{*}{ C3 } & \multirow{4}{*}{0.091} & $\mathrm{SO}_{2} \mathrm{C} 3-1$ & 0.238 \\
\hline & & & Rn C3-2 & 0.344 \\
\hline & & & $\mathrm{CO} \mathrm{C} 3-3$ & 0.217 \\
\hline & & & TSP C3-4 & 0.201 \\
\hline \multirow{3}{*}{ Ecological compensation indicators } & \multirow{3}{*}{ C6 } & \multirow{3}{*}{0.131} & Input intensity of pollution control C6-1 & 0.416 \\
\hline & & & Improvement of ecological early warning system C6-2 & 0.302 \\
\hline & & & Environmental protection investment/total income C6-3 & 0.282 \\
\hline
\end{tabular}

TABLE 5: The grading standard of the relative importance of the corresponding index to the goal.

\begin{tabular}{lc}
\hline Logical variable & $\begin{array}{c}\text { Grade corresponding to factor weight } \\
\text { ratio }\end{array}$ \\
\hline Equally important & 0.96 \\
Weakly important & 0.8 \\
Fairly important & 0.64 \\
Strongly important & 0.48 \\
Very strongly & 0.32 \\
important & 0.16 \\
Extremely important &
\end{tabular}

fuzzy variable $z$, respectively, all of which are real numbers. Then, the three numbers $(l, m, u)$ constitute a triangular fuzzy number, $\tilde{A}$. Let $\tilde{A}=(l, m, u)$ and $l \leq m \leq u$, and the function diagram of the triangular fuzzy number is shown in Figure 1. The membership function [18] is

$$
\varepsilon(z)=\left\{\begin{array}{ll}
0 & z<l \\
\frac{z-l}{m-l} & l \leq z \leq m \\
\frac{u-z}{u-m} & m \leq z \leq u \\
0 & z \geq u
\end{array},\right.
$$

where the parameter $m$ denotes the maximum possible value describing a fuzzy event, and $l$ and $u$ represent the upper and lower bounds of the boundary, respectively. 
TABLE 6: The comparison matrix with respect to the goal.

\begin{tabular}{ccccc}
\hline & \multicolumn{4}{c}{ Present method } \\
& $\mathrm{C} 1$ & $\mathrm{C} 2$ & $\mathrm{C} 3$ & $\mathrm{C} 6$ \\
\hline $\mathrm{C} 1$ & $(1,1,1)$ & $(2 / 3,1,2)$ & $(2,5 / 2,3)$ & $(3 / 2,2,5 / 2)$ \\
$\mathrm{C} 2$ & $(1 / 2,1,3 / 2)$ & $(1,1,1)$ & $(2,5 / 2,3)$ & $(3 / 2,2,5 / 2)$ \\
$\mathrm{C} 3$ & $(1 / 3,2 / 5,1 / 2)$ & $(1 / 3,2 / 5,1 / 2)$ & $(1,1,1)$ & $(2 / 3,1,2)$ \\
$\mathrm{C} 6$ & $(2 / 5,1 / 2,2 / 3)$ & $(2 / 5,1 / 2,2 / 3)$ & $(1 / 2,1,3 / 2)$ & $(1,1,1)$ \\
\hline
\end{tabular}

$\lambda=0.4798, M=1015$.

2.2. Generalized Linear Model Theory. The generalized linear model is a direct extension of the normal linear model, which is suitable for continuous data and discrete data; that is, the independent variable can be a continuous variable, classified variable, or ordered variable. Its basic form can be expressed as

$$
\mu_{i}=E\left[Y_{i}\right]=g^{-1}\left(\sum_{j} X_{i j} \beta_{j}+\xi_{i}\right)
$$

where $\mu_{i}$ is the mathematical expectation; $Y_{i}$ is the dependent variable vector; $g(x)$ is the connection function; $X_{i j}$ is the independent variable matrix; $\beta_{j}$ is the model parameter vector to be estimated; and $\xi_{i}$ is the interference term.

Combined with equation (3), the observed value of the dependent variable can be connected with the expected value of the explanatory variable by linear addition; therefore, the relationship between the mathematical expectation $\mu_{i}$ and the linear factors can be expressed as

$$
g\left(\mu_{i}\right)=X_{i} \beta^{\prime}
$$

where $g\left(\mu_{i}\right)$ is a strictly monotonic function and is differentiable, which is called a continuous function.

The expected value of the observed value of the dependent variable is related to the explanatory variable by equation (4-1). It is assumed that there are $\mathrm{N}$ sets of observation data, i.e., $\left(\mathrm{y} \mid X_{i}\right)=\left(\mathrm{y} \mid x_{1}, x_{2}, \cdots, x_{k}\right)$ and $(i=1,2, \cdots, n) . \mathrm{y}_{\mathrm{i}} \in(0$, $1, \cdots, j)$ is a multicategory dependent variable with $j$ categories, indicating that the conclusion of the safety evaluation model has $j$ grades. $X=\left(x_{1}, x_{2}, \cdots, x_{k}\right)$ is the explanatory variable, i.e., the influencing factor affecting the conclusion grade of the model.

It is assumed that $\omega_{i}$ is the cumulative influence weight of a certain level $y_{i}$ under the condition of the index factor variable

$$
\omega_{i}=\omega\left(y_{i} \leq j \mid X_{i}\right), \omega_{i}=\omega_{i+1}-\omega_{i},
$$

where $\bar{\omega}_{i}$ is the influence weight of an evaluation level.

To better describe the relationship between the cumulative influence weight of the level and the index factor variables, in this paper, the relationship is transformed by logistic transformation, that is

$$
\log i t\left(\omega_{i}\right)=\ln \left[\frac{\omega_{i}\left(y_{i} \leq j \mid x_{i}\right)}{1-\omega_{i}\left(y_{i} \leq j \mid x_{i}\right)}\right]=\beta_{0}+\sum_{i=0}^{k} \beta_{i} x_{i},
$$

where the relationship between the logit $(\omega)$ transformed and the independent variable is linear, and its value range is $(-\infty$, $+\infty)$, which is conducive to its estimation.

The regression equation can be obtained by substituting the estimated value of parameter $\beta$ into equation (6)

$$
\omega^{\prime}\left(y_{i} \leq j \mid\left(x_{1}, x_{2}, \cdots, x_{k}\right)_{i}\right)=\frac{\exp \left(\beta_{0}^{\prime}+\sum_{i=0}^{k} \beta_{0}^{\prime} x_{i}\right)}{1+\exp \left(\beta_{0}^{\prime}+\sum_{i=0}^{k} \beta_{0}^{\prime} x_{i}\right)}
$$

2.3. The Fuzzy Analytic Hierarchy Process. First, the weight value of each index influencing the target value is determined by generalized linear theory, and then the importance of each pair of factors is judged by the weight of each index factor. According to the linguistic variable in Table 1, the relative importance of each pair of factors can be obtained. Then, the comparison matrix $\tilde{U}$ can be created.

$\tilde{U}=\left(\tilde{u}_{i j}\right)_{n \times n}=\left[\begin{array}{cccc}1 & \left(l_{12}, m_{12}, u_{12}\right) & \cdots & \left(l_{1 n}, m_{1 n}, u_{1 n}\right) \\ \left(l_{21}, m_{21}, u_{21}\right) & 1 & \cdots & \left(l_{2 n}, m_{2 n}, u_{2 n}\right) \\ \vdots & \vdots & \vdots & \vdots \\ \left(l_{n 1}, m_{n 1}, u_{n 1}\right) & \left(l_{n 2}, m_{n 2}, u_{n 2}\right) & \cdots & 1\end{array}\right]$,

where if $i \neq j$, then $\tilde{u}_{i j}=\left(l_{i j}, m_{i j}, u_{i j}\right)=\tilde{u}_{i j}{ }^{-1}=\left(1 / u_{j i}, 1 / m_{j i}, 1\right.$ $\left./ l_{j i}\right),(i=1,2, \cdots, n)$, and $(j=1,2, \cdots, n)$.

To facilitate the research, the comparison matrix $\tilde{U}$ is processed by the logarithmic transformation $[19,20]$

$$
\ln \tilde{u}_{i j} \approx\left(\ln l_{i j}, \ln m_{i j}, \ln u_{i j}\right)
$$

By substituting equation (9) into equation (2), the following can be obtained

$$
\mu_{i j}\left(\ln \left(\frac{s_{i}}{s_{j}}\right)\right)=\left\{\begin{array}{ll}
0 & \ln \left(\frac{s_{i}}{s_{j}}\right)<\ln l_{i j} \\
\frac{\ln \left(s_{i} / s_{j}\right)-\ln l_{i j}}{\ln m_{i j}-\ln l_{i j}} & \ln l_{i j} \leq \ln \left(\frac{s_{i}}{s_{j}}\right) \leq \ln m_{i j} \\
\frac{\ln u_{i j}-\ln \left(s_{i} / s_{j}\right)}{\ln u_{i j}-\ln m_{i j}} & \ln m_{i j} \leq \ln \left(\frac{s_{i}}{s_{j}}\right) \leq \ln u_{i j} \\
0 & \ln \left(\frac{s_{i}}{s_{j}}\right)>\ln u_{i j}
\end{array} .\right.
$$


TABLe 7: The comparison matrix with respect to the soil quality.

\begin{tabular}{lccccc}
\hline & & \multicolumn{2}{c}{ Present method } & C1-4 & C1-5 \\
\hline $\mathrm{C} 1-1$ & $\mathrm{C} 1-2$ & $(2,5 / 2,3)$ & $(3 / 2,2,5 / 2)$ & $(2,5 / 2,3)$ & $(2 / 3,1,2)$ \\
$\mathrm{C} 1-2$ & $(1,1,1)$ & $(1,1,1)$ & $(2 / 3,1,2)$ & $(2 / 3,1,2)$ & $(1 / 3,2 / 5,1 / 2)$ \\
$\mathrm{C} 1-3$ & $(1 / 3,2 / 5,1 / 2)$ & $(1 / 2,1,3 / 2)$ & $(1,1,1)$ & $(1 / 2,1,3 / 2)$ & $(2 / 5,1 / 2,2 / 3)$ \\
$\mathrm{C} 1-4$ & $(2 / 5,1 / 2,2 / 3)$ & $(1 / 2,1,3 / 2)$ & $(2 / 3,1,2)$ & $(1,1,1)$ & $(1 / 3,2 / 5,1 / 2)$ \\
$\mathrm{C} 1-5$ & $(1 / 3,2 / 5,1 / 2)$ & $(2,5 / 2,3)$ & $(3 / 2,2,5 / 2)$ & $(2,5 / 2,3)$ & $(1,1,1)$ \\
\hline
\end{tabular}

$\lambda=0.8200, M=1018$.

TABle 8: The comparison matrix with respect to the water environmental quality.

\begin{tabular}{ccccc}
\hline & \multicolumn{4}{c}{ Present method } \\
& C2-1 & C2-2 & C2-3 & C2-4 \\
\hline C2-1 & $(1,1,1)$ & $(3 / 2,2,5 / 2)$ & $(1,3 / 2,2)$ & $(1,3 / 2,2)$ \\
C2-2 & $(2 / 5,1 / 2,2 / 3)$ & $(1,1,1)$ & $(1 / 2,2 / 3,1)$ & $(1 / 2,2 / 3,1)$ \\
C2-3 & $(1 / 2,2 / 3,1)$ & $(1,3 / 2,2)$ & $(1,1,1)$ & $(2 / 3,1,2)$ \\
C2-4 & $(1 / 2,2 / 3,1)$ & $(1,3 / 2,2)$ & $(1 / 2,1,3 / 2)$ & $(1,1,1)$ \\
\hline
\end{tabular}

$\lambda=0.6230, M=1017$.

TABLE 9: The comparison matrix with respect to the atmospheric environment.

\begin{tabular}{ccccc}
\hline & \multicolumn{4}{c}{ Present method } \\
& C3-1 & C3-2 & C3-3 & C3-4 \\
\hline C3-1 & $(1,1,1)$ & $(2 / 3,1,2)$ & $(1 / 2,1,3 / 2)$ & $(1,3 / 2,2)$ \\
C3-2 & $(1 / 2,1,3 / 2)$ & $(1,1,1)$ & $(1,3 / 2,2)$ & $(1,3 / 2,2)$ \\
C3-3 & $(2 / 3,1,2)$ & $(1 / 2,2 / 3,1)$ & $(1,1,1)$ & $(1 / 2,1,3 / 2)$ \\
C3-4 & $(1 / 2,2 / 3,1)$ & $(1 / 2,2 / 3,1)$ & $(2 / 3,1,2)$ & $(1,1,1)$ \\
\hline
\end{tabular}

$\lambda=0.4819, M=1015$.

In this paper, to solve the problem that a specific value $\lambda$ results in an inconsistency between weights and fuzzy judgements in $U$, the nonnegative deviation parameters of $\gamma_{i j}$ are introduced $[17,18]$.

$$
\begin{aligned}
\operatorname{Minimize} K=(1-\lambda)^{2}+G \sum_{i=1}^{n-1} \sum_{j=i+1}^{n}\left(\gamma_{i j}+\varsigma_{i j}\right)^{2} \text { S.t. } \\
\qquad\left\{\begin{array}{l}
\ln s_{i}-\ln s_{j}-\lambda \ln \left(\frac{m_{i j}}{l_{i j}}\right)+\gamma_{i j} \geq \ln l_{i j} \\
i=1, \cdots, n-1 ; j=i+1, \cdots, n \\
-\ln s_{i}+\ln s_{j}-\lambda \ln \left(\frac{u_{i j}}{m_{i j}}\right)+\varsigma_{i j} \geq-\ln u_{i j} \\
i=1, \cdots, n-1 ; j=i+1, \cdots, n \\
\lambda \geq 0, y_{i} \geq 0, i=1, \cdots, n-1 \\
\gamma_{i j} \geq 0, \varsigma_{i j} \geq 0, i=1, \cdots, n-1 ; j=i+1, \cdots, n
\end{array}\right.
\end{aligned}
$$

TABLE 10: The comparison matrix with respect to ecological compensation.

\begin{tabular}{lccc}
\hline & & Present method & \\
& C6-1 & C6-2 & C6-3 \\
\hline C6-1 & $(1,1,1)$ & $(1 / 2,1,3 / 2)$ & $(1,3 / 2,2)$ \\
C6-2 & $(2 / 3,1,2)$ & $(1,1,1)$ & $(1 / 2,1,3 / 2)$ \\
C6-3 & $(1 / 2,2 / 3,1)$ & $(2 / 3,1,2)$ & $(1,1,1)$ \\
\hline
\end{tabular}

$\lambda=0.6017, M=1012$.

where $G$ is a specific constant, which is used to determine the weights in the fuzzy judgements.

The normalized priority calculation of the fuzzy pairwise comparison matrix $\tilde{U}$ can be expressed by

$$
\omega_{i}^{*}=\frac{\exp \left(\left(\ln s_{i}\right)^{*}\right)}{\sum_{j=1}^{n} \exp \left(\left(\ln s_{j}\right)^{*}\right)} .
$$

\section{Application}

3.1. Determination of Index Factors. According to the survey, the main indicators affecting the ecological safety of coal mines are atmospheric environmental indicators, water environmental quality indicators, soil quality indicators, geological hazard damage indicators, waste disposal indicators of coal mines, and ecological compensation indicators of coal mines. Among them, atmospheric environmental indicators mainly include factors affecting atmospheric environmental safety, e.g., TSP, $\mathrm{CO}, \mathrm{SO}_{2}$, and radon. Water environmental quality indicators mainly include the concentrations of $\mathrm{Pb}$, $\mathrm{Zn}, \mathrm{COD}$, and BOB. Soil quality indicators mainly refer to the concentrations of coal, lead, cadmium, zinc, and arsenic. The index of the degree of destruction of geological hazards mainly refers to the proportion of all kinds of geological hazards in the total area of mines, i.e., the impact scale of landslides, collapses, and land subsidence. The waste disposal indexes of coal mines mainly include slag disposal and waste liquid controlled discharge. The ecological compensation index of coal mines includes the input intensity of pollution control, the perfection of ecological early warning mechanisms, and the proportion of environmental protection input to mine income.

3.2. Determine the Weights of the Responding Index Factors. The decision problem in the hierarchical structure is decomposed, as shown in Figure 2. The hierarchy consists of three levels, including goals, criteria and alternatives. This goal 
TABLE 11: The priorities of risk factors to the coal mine.

\begin{tabular}{|c|c|c|c|}
\hline Factors & Local weight & Global weight & Ranking \\
\hline Soil quality $\mathrm{C} 1$ & & 0.6655 & $\mathrm{I}$ \\
\hline Concentration of coal C1-1 & 0.4521 & 0.3009 & 1 \\
\hline Concentration of lead C1-2 & 0.1481 & 0.0986 & 4 \\
\hline Concentration of cadmium C1-3 & 0.1827 & 0.1215 & 3 \\
\hline Concentration of zinc C1-4 & 0.1085 & 0.0722 & 6 \\
\hline Concentration of arsenic C1-5 & 0.1086 & 0.0723 & 5 \\
\hline Water environmental quality C2 & & 0.2293 & II \\
\hline Concentration of $\mathrm{Pb} \mathrm{C} 2-1$ & 0.7002 & 0.1606 & 2 \\
\hline Concentration of $\mathrm{Zn} \mathrm{C2-2}$ & 0.1339 & 0.0308 & 8 \\
\hline Concentration of COD C2-3 & 0.1060 & 0.0242 & 9 \\
\hline Concentration of BOB C2-4 & 0.0599 & 0.0137 & 11 \\
\hline Atmospheric environment $\mathrm{C} 3$ & & 0.0679 & III \\
\hline Concentration of TSP C3-1 & 0.7754 & 0.0526 & 7 \\
\hline Concentration of CO C3-2 & 0.1871 & 0.0127 & 12 \\
\hline Concentration of $\mathrm{SO} 2 \mathrm{C} 3-3$ & 0.0322 & 0.0022 & 15 \\
\hline Concentration of radon $\mathrm{C} 3-4$ & 0.0053 & 0.0004 & 16 \\
\hline Ecological compensation indicators C6 & & 0.0373 & IV \\
\hline Input intensity of pollution control C6-1 & 0.3790 & 0.0141 & 10 \\
\hline Perfection of ecological early warning mechanism C6-2 & 0.3313 & 0.0124 & 13 \\
\hline Proportion of environmental protection input to mine income C6-3 & 0.2896 & 0.0108 & 14 \\
\hline
\end{tabular}

TABLE 12: The consistency of each fuzzy comparison matrix.

\begin{tabular}{lc}
\hline Hierarchy & Consistency $\lambda$ \\
\hline Soil quality indicators (Table 7) & 0.8200 \\
Water environmental quality (Table 8) & 0.6230 \\
Atmospheric environment (Table 9) & 0.4819 \\
Ecological compensation indicators (Table 10) & 0.6017 \\
\hline
\end{tabular}

layer is mainly used to assess the ecological environmental risk of coal mines. The criteria and alternatives are located at the second level and the third level, respectively.

The ecological environment monitoring data of several typical coal mines in China are selected to evaluate the ecological environmental safety. The ecological compensation index is generally calculated by comprehensively considering the benefits of the mine, the income expectations of leaders and miners, and the laws and regulations. The data of influencing factors of air, soil, and water indexes are mainly collected from the concentration of some harmful substances specified in relevant national standards. Based on the analysis of the evaluation indexes of the coal mine according to references [21-26], the ecological safety compensation index value and the index factor index value of air, soil, and water indexes of the coal mine are obtained, as shown in Tables 2 and 3.

The cumulative influence weight of the corresponding grade of the first level indicator and the influence weight of each grade under the second level indicator factor are obtained through the analysis of the generalized linear model (the influence weight of each grade indicator is mainly obtained through the Statistical Analysis System (SAS), as shown in Table 4), and then the maximum value of the influence weight of each grade is taken as the influence weight of the corresponding category. The weight of each index factor is used to judge the relative importance of each index factor. The maximum likelihood ratio of each category is 42.684 , $35.033,43.556$, and 41.022, respectively, all of which are within the allowable error range, indicating that the generalized linear model has a good fit.

The influence weight of the grade corresponding to the second level index and its corresponding first level index is analyzed through the generalized linear model, and the comparison matrix of the first level index and the second level index can be obtained according to Table 5, as shown in Tables 6-10.

\section{Results and Discussion}

4.1. Results. The results of local and global weights on the environmental impact factors of coal mines obtained by the present evaluation model based on the generalized linear and fuzzy analytic hierarchy process are shown in Table 11, which shows that the soil quality has the most important index influence on the environmental risk of coal mines among the four influencing factors, followed by water environmental quality, atmospheric environment, and ecological compensation indicators. Therefore, it is necessary to monitor the dangerous elements in soil and water on a regular basis and take timely measures to prevent exceeding the standard to control the dangerous sources during the early risk stage. 
TABLE 13: The priorities of risk factors to the coal mine [27].

\begin{tabular}{|c|c|c|c|}
\hline Factors & Local weight & Global weight & Ranking \\
\hline Soil quality $\mathrm{C} 1$ & & 0.478 & $\mathrm{I}$ \\
\hline Concentration of coal C1-1 & 0.5588 & 0.2671 & 1 \\
\hline Concentration of lead C1-2 & 0.0967 & 0.0462 & 6 \\
\hline Concentration of cadmium C1-3 & 0.2219 & 0.1061 & 3 \\
\hline Concentration of zinc $\mathrm{C} 1-4$ & 0.0663 & 0.0317 & 9 \\
\hline Concentration of arsenic C1-5 & 0.0563 & 0.0269 & 10 \\
\hline Water environment quality $\mathrm{C} 2$ & & 0.363 & II \\
\hline Concentration of $\mathrm{Pb} \mathrm{C} 2-1$ & 0.6903 & 0.2506 & 2 \\
\hline Concentration of Zn C2-2 & 0.1493 & 0.0542 & 5 \\
\hline Concentration of COD C2-3 & 0.1118 & 0.0406 & 7 \\
\hline Concentration of BOB C2-4 & 0.0485 & 0.0176 & 13 \\
\hline Atmospheric environment C3 & & 0.0831 & III \\
\hline Concentration of TSP C3-1 & 0.7449 & 0.0619 & 4 \\
\hline Concentration of CO C3-2 & 0.2358 & 0.0196 & 12 \\
\hline Concentration of SO2 C3-3 & 0.0168 & 0.0014 & 15 \\
\hline Concentration of radon $\mathrm{C} 3-4$ & 0.0025 & 0.0002 & 16 \\
\hline Ecological compensation indicators C6 & & 0.0759 & IV \\
\hline Input intensity of pollution control C6-1 & 0.4598 & 0.0349 & 8 \\
\hline Perfection of ecological early warning mechanism C6-2 & 0.3083 & 0.0234 & 11 \\
\hline Proportion of environmental protection input to mine income C6-3 & 0.2319 & 0.0176 & 14 \\
\hline
\end{tabular}

In addition, Table 11 shows that the concentration of coal (C1-1), concentration of $\mathrm{Pb}(\mathrm{C} 2-1)$, concentration of cadmium (C1-3), and concentration of lead (C1-2) have a great influence on the environmental risk of coal mines. However, the perfection of an ecological early warning mechanism (C6-2), proportion of environmental protection input to mine income (C6-3), concentration of $\mathrm{SO}_{2}$ (C3-3), and concentration of radon (C3-4) have little influence on the environmental risk of coal mines. Table 11 also reveals that the environmental investment management of coal mines in the later stage has little impact on the environmental assessment. This result is mainly because in the later stage, the environment of coal mines has caused many irreversible losses and has had many human and financial costs. From a sustainable point of view, the compensation and management of the mine environment in the later period are definitely not a good long-term strategy.

4.2. Verification of the model's Validity. According to the literature, the validity of a model is usually verified by calculating the value of consistency and the nonnegative deviation variable of the fuzzy pairwise comparison matrices, i.e., the consistency $\lambda$ and nonnegative deviation variable $\gamma$ are the key parameters to determine the validity of a model. There are two cases in which $\lambda=0$ and $\lambda \neq 0$. When $\lambda$ is not equal to zero, the greater the value of parameter $\lambda$ is, the better the consistency of the model is. When $\lambda$ is equal to zero, if $\gamma=0$, the consistency of the model is still good. If $\gamma \neq 0$, it indicates that the model is inconsistent. The greater the nonnegative deviation variable $\gamma$ is, the worse the consistency of the model is. With the help of MATLAB software, the value of $\lambda$ in every matrix is obtained, as shown in Table 12. From the consistency index aspect, the proposed model is confirmed to be acceptable.

In the second perspective, we compare the results of the present method we used in this paper with the results of the representative comprehensive evaluation method [27]. The results of the representative comprehensive evaluation method are shown in Table 13. We have obtained similar results on some factors. In particular, the impact of the first level index factors on the safety environment of uranium mines is basically the same. From all above, the proposed model was proven to be valid.

4.3. Advantages and Disadvantages of the Present Model. Based on generalized linear theory, the influence value of index factors on the environmental evaluation of coal mines was obtained using SAS software to count the original data of the index factors. Then, the fuzzy pairwise comparison matrices were established according to the influence value of index factors on the environmental evaluation, which greatly reduced the influence of human subjectivity on the construction of the comparison matrix. In addition, the linguistic variables and the TFN were introduced in the process of solving the factor weight, which enabled managers to quickly determine the relative importance of each pair of factors through the linguistic variables.

However, in the present model, although the importance degree of each factor was obtained using a linear generalized model to count the original data of each factor, the relative importance degree of each factor was judged by experts. Therefore, it is urgent to establish an evaluation formula and basis for the relative importance degree of each factor. In addition, according to the literature, although the 
comparison matrices are consistent, the fuzzy number of the comparison matrix can lead to inconsistent results to some extent.

\section{Conclusions}

This paper develops a comprehensive environmental evaluation model of coal mines based on generalized linear theory and fuzzy analytic hierarchy processes.

(1) The model is consistent with the results of literature [27] and let the evaluation process more efficient

(2) In this paper, the linguistic variables are a kind of variable whose values are not numbers but words or sentences, and they are closer to the feelings of the decision makers. Therefore, the present model can effectively solve the problem of multiclassification in safety evaluations

(3) In addition, in the environmental evaluation model, based on prior knowledge of the sample statistical source, the importance degree of each index factor on the environmental factor index is preliminarily obtained through generalized linear theory, and the influence weight value of each index factor was accurately obtained based on the logarithmic fuzzy preference programming method, which overcomes the defect of artificial empowerment and has more accurate evaluation results

\section{Data Availability}

The data used to support the findings of this study are included within the article.

\section{Conflicts of Interest}

The authors declare that they have no conflicts of interest.

\section{Acknowledgments}

This work was supported by the Postdoctoral research projects in Henan Province (201901012), the National Key Research and Development Program of China (No. 2017YFC1501204), the National Basic Research Program of China (No. 2015CB060200), the National Natural Science Foundation of China (No. 51678536, 41404096), the Program for Science and Technology Innovation Talents in Universities of Henan Province (Grant No. 19HASTIT043), the Outstanding Young Talent Research Fund of Zhengzhou University (1621323001), and the Program for Innovative Research Team (in Science and Technology) in University of Henan Province (18IRTSTHN007). We would also like to acknowledge the reviewers for their invaluable comments.

\section{References}

[1] L. Dong, X. Tong, X. Li, J. Zhou, S. Wang, and B. Liu, "Some developments and new insights of environmental problems and deep mining strategy for cleaner production in mines," Journal of Cleaner Production, vol. 210, pp. 1562-1578, 2019.

[2] A. M. R. Neiva, P. C. S. Carvalho, I. M. H. R. Antunes et al., "Assessment of metal and metalloid contamination in the waters and stream sediments around the abandoned uranium mine area from Mortórios, Central Portugal," Journal of Geochemical Exploration, vol. 202, pp. 35-48, 2019.

[3] L. Dong, D. Sun, W. Shu, and X. Li, "Exploration: safe and clean mining on earth and asteroids," Journal of Cleaner Production, vol. 257, article 120899, 2020.

[4] Y. Zhao, "Study and applications of analytic hierarchy process of mine geological environment: a case study in Hainan Island," Remote Sensing for Land and Resources, pp. 1-9, 2020.

[5] A. Bascetin, "A decision support system using analytical hierarchy process (AHP) for the optimal environmental reclamation of an open-pit mine," Environmental Geology, vol. 52, no. 4, pp. 663-672, 2007.

[6] C. Samantra, S. Datta, and S. Mahapatra, "Analysis of occupational health hazards and associated risks in fuzzy environment: a case research in an Indian underground coal mine," International Journal of Injury Control and Safety Promotion, vol. 24, no. 3, pp. 311-327, 2016.

[7] M. Yang, L. Liu, and G. Gao, "Application of fuzzy synthesis evaluation to the environmental influence of the westmineral exploration," Journal of Xi'an University of Science and Technology, vol. 26, no. 4, pp. 439-442, 2006.

[8] X. Su, F. Cheng, S. Guo, and J. Zhou, "Evaluation model of mine engineering geological conditions based on grey mathematics theory," Mining Technology, vol. 16, no. 5, pp. 87-89, 2016.

[9] W. Zhao, M. Xu, J. Zhang, and S. Qi, “Application of BP neural network in mine ecological security evaluation," Coal Technology, vol. 38, no. 1, pp. 172-175, 2019.

[10] Z. Chen, J. Wu, Y. Guo, and T. Lin, "Application of AHP and fuzzy mathematics in comprehensive assessment of mine environment," East China Geology, vol. 39, no. 4, pp. 305-310, 2018.

[11] D. Wei, C. Du, Y. Lin, B. Chang, and Y. Wang, "Thermal environment assessment of deep mine based on analytic hierarchy process and fuzzy comprehensive evaluation," Case Studies in Thermal Engineering, vol. 19, article 100618, 2020.

[12] L. Dong, W. Shu, X. Li, Z. Zhou, F. Gong, and X. Liu, "Quantitative evaluation and case study of risk degree for underground Goafs with multiple indexes considering uncertain factors in mines," Geofluids, vol. 2017, Article ID 3271246, 15 pages, 2017.

[13] L. Dong and X. Li, "Comprehensive models for evaluating rockmass stability based on statistical comparisons of multiple classifiers," Mathematical Problems in Engineering, vol. 2013, Article ID 395096, 9 pages, 2013.

[14] Y. Wei, G. Tong, and Z. Ji, "Fuzzy hierarchy analysis model for the mine management based on grey correlation degree," China Molybdenum Industry, vol. 19, no. 3, pp. 28-32, 1995.

[15] F. Liu, Research on the Combination Evaluation Model of Mine Geological Environment Based on Grey Correlation Degree, AHP and Fuzzy, Chang'an University, 2014.

[16] T. Padma and P. Balasubramanie, "A fuzzy analytic hierarchy processing decision support system to analyze occupational menace forecasting the spawning of shoulder and neck pain," Expert Systems with Applications, vol. 38, no. 12, pp. 1530315309, 2011. 
[17] Q. Wang, H. Wang, and Z. Qi, “An application of nonlinear fuzzy analytic hierarchy process in safety evaluation of coal mine," Safety Science, vol. 86, pp. 78-87, 2016.

[18] M. Naghadehi, R. Mikaeil, and M. Ataei, "The application of fuzzy analytic hierarchy process (FAHP) approach to selection of optimum underground mining method for Jajarm bauxite mine, Iran," Expert Systems with Applications, vol. 36, no. 4, pp. 8218-8226, 2009.

[19] L. Zadeh, "The concept of a linguistic variable and its application to approximate reasoning," Learning Systems and Intelligent Robots, vol. 8, pp. 199-249, 1974.

[20] M. Dağdeviren and I. Yüksel, "Developing a fuzzy analytic hierarchy process (AHP) model for behavior-based safety management," Information Sciences, vol. 178, no. 6, pp. 1717-1733, 2008.

[21] Y. Zhang, "Ecological security evaluation and policy suggestions of coal industry in China," Theory Monthly, vol. 2, pp. 163-165, 2011.

[22] F. Zhang, Assessment on Wetland Ecosystem Based on $3 S$ Image-Taking the Heihe Rivesource Qilian Mountains as an Example, Qinghai Normal University, Xining, 2011.

[23] K. Yang, "Application of fuzzy mathematics in mine environmental impact assessment," Sichuan Environment, vol. 29, no. 3, pp. 127-130, 2010.

[24] GB 3095-2012, “Ambient air quality standard," http://www .cssn.net.cn/cssn/front/listpage.jsp.

[25] GB 15618-1995, "Soil environmental quality standard," http:// www.cssn.net.cn/cssn/front/listpage.jsp.

[26] GB 3838-2002, "Environmental quality standard for surface water," http://www.cssn.net.cn/cssn/front/listpage.jsp.

[27] L. Dong, W. Shu, X. Li, and J. Zhang, "Quantitative evaluation and case studies of cleaner mining with multiple indexes considering uncertainty factors for phosphorus mines," Journal of Cleaner Production, vol. 183, pp. 319-334, 2018. 